\title{
Impact of methamphetamine on infection and immunity
}

\author{
Sergio A. Salamanca ${ }^{1}$, Edra E. Sorrentino ${ }^{1}$, Joshua D. Nosanchuk ${ }^{2,3}$ and Luis R. Martinez ${ }^{4 *}$ \\ ${ }^{1}$ Department of Biomedical Sciences, Long Island University-Post, Brookville, NY, USA \\ ${ }^{2}$ Microbiology and Immunology, Albert Einstein College of Medicine, Bronx, NY, USA \\ ${ }^{3}$ Medicine (Division of Infectious Diseases), Albert Einstein College of Medicine, Bronx, NY, USA \\ ${ }^{4}$ Department of Biomedical Sciences, NYIT College of Osteopathic Medicine, New York Institute of Technology, Old Westbury, NY, USA
}

\section{Edited by:}

Jacob Raber, Oregon Health and

Science University, USA

\section{Reviewed by:}

Eugene A. Kiyatkin, National

Institute on Drug Abuse, USA

Gillian Grafton, University of

Birmingham, UK

*Correspondence:

Luis R. Martinez, New York Institute

of Technology, College of

Osteopathic Medicine, Northern

Boulevard, PO Box 8000 Riland

Building, Room 28 Old Westbury,

NY 11568-8000, USA

e-mail:Imarti13@nyit.edu
The prevalence of methamphetamine (METH) use is estimated at $\sim 35$ million people worldwide, with over 10 million users in the United States. METH use elicits a myriad of social consequences and the behavioral impact of the drug is well understood. However, new information has recently emerged detailing the devastating effects of METH on host immunity, increasing the acquisition of diverse pathogens and exacerbating the severity of disease. These outcomes manifest as modifications in protective physical and chemical defenses, pro-inflammatory responses, and the induction of oxidative stress pathways. Through these processes, significant neurotoxicities arise, and, as such, chronic abusers with these conditions are at a higher risk for heightened consequences. METH use also influences the adaptive immune response, permitting the unrestrained development of opportunistic diseases. In this review, we discuss recent literature addressing the impact of METH on infection and immunity, and identify areas ripe for future investigation.

Keywords: methamphetamine, infectious diseases, immunity, drug abuse, HIV, neurotoxicity

\section{METHAMPHETAMINE (METH), A MAJOR PUBLIC HEALTH PROBLEM}

The growing popularity of Methamphetamine (METH), a street drug associated with the severe neurological and physical consequences afflicting its users, has created an increasingly serious public health problem worldwide. In a 2011 United Nations survey, approximately $2.5 \%$ of Australians over the age of 14 have tried METH, a prevalence rate three to five times higher than those seen in the United States (USA), Canada, and the United Kingdom (United Nations, 2011). In the USA, over one million individuals aged 12 years and older-roughly $0.5 \%$ of the American population-were reported to have sampled METH (Colfax and Shoptaw, 2005; United Nations, 2011). According to the USA Department of Justice, after alcohol and marijuana, $\mathrm{METH}$ is the most commonly used recreational drug in many states (Drug Enforcement Administration, 2007).

METH is a potent central nervous system (CNS) stimulant that mimics the pharmacological effects of cocaine. The "rush" that follows METH use is associated with the release of neurotransmitters, including adrenaline, dopamine, and serotonin (Downes and Whyte, 2005; Collins et al., 2014). Whereas the halflife of cocaine is measured in minutes, however, that of METH is measured in hours $(\sim 8$ to $24 \mathrm{~h})$. Thus, the pharmacological effects of METH are thus longer lasting than cocaine. In spite of the potentially dangerous consequences of METH use, the drug retains its popularity as a low-cost alternative to cocaine and heroin. The relative ease of METH production has ensured that prices remain low, particularly in Australia, where METH use is more prevalent and widespread than in most other countries (Marwick, 2000; United Nations, 2011; Gong et al., 2012). In recent years, however, the upsurge of drug enforcement and control policies has significantly limited the availability of precursor chemicals essential for METH production, raising purchase prices and reducing the overall demand for the product (Drug Enforcement Administration, 2007; Gong et al., 2012). General METH use is seen as minimal exposure to the drug, primarily involving first time users; whereas, chronic METH abuse and dependence expose the user to a diverse range of adverse physical and cognitive health consequences (Panenka et al., 2013). The rate of treatment admissions for primary METH abuse has increased over 3-fold in recent years (Colfax and Shoptaw, 2005).

Diverse routes for METH use exist, including oral ingestion, smoking, snorting, intravenous injection, and anal insertion. The intravenous administration of METH has become a popular usage mechanism due to its ability to deliver almost immediate effects of euphoria (Hart et al., 2008). The sharing of drug paraphernalia combined with METH's perceived enhancement of sexual pleasure and the association of its use with unsafe sexual practices greatly increases the likelihood of the acquisition of human immunodeficiency virus (HIV) and other infectious diseases (Ellis et al., 2003; Urbina et al., 2004; Mansergh et al., 2006; Nakamura et al., 2011). In addition, animal studies demonstrate that METH suppresses both innate and adaptive immunity (In et al., 2005; Peerzada et al., 2013). This review explores recent research developments related to the effects of METH on infection and immunity.

\section{PHARMACOLOGICAL METH LEVELS IN HUMANS}

The S-(+) enantiomer of METH ((S)-N-Methyl-1-phenylpropan-2-amine), dextromethamphetamine, is popularly used among METH users for its potent effect on the cardiovascular system and CNS (Li et al., 2010; Volkow et al., 2010). Patterns 
of METH intake are variable depending on the user; a selfreporting study indicated that a majority of chronic METH users consume the drug more than 20 days per month, at a frequency of 1-3 doses per day (Saito et al., 2008). Typically, people take 5-15 mg (low stimulation), 10-30 (common dose), and $20-60 \mathrm{mg}$ (strong) with both per-oral and intravenous (i.v.) administration (Hart et al., 2008; Cruickshank and Dyer, 2009). Following ingestion, the metabolism of METH takes place in the liver, where the cytochrome P4502D6 causes Ndemethylation and aromatic hydroxylation, forming the primary metabolites para-hydroxymethamphetamine (pOH-MA) and amphetamine (AMP). Afterwards, the primary and other minor metabolites (norephedrine, 4-hydroxyamphetamine, 4hydroxynorephenedrine, benzyl methyl ketoxime and benzoic acid) are absorbed across the gastrointestinal tract. The concentration peak of METH in plasma after oral ingestion can be detected at 3.13-6.3 h post-consumption and its metabolites peak at $10-24 \mathrm{~h}$ (Gartner and Liu, 2002). The metabolite pOH-MA is therefore one of the most stable biomarkers of METH abuse (Li et al., 2010).

$\mathrm{METH}$ is often used in binges, and as the drug exhibits a half-life of 11.4-12 h (Cho et al., 2001; Harris et al., 2003). Recently published studies modeling binge patterns show that after the fourth administration of $260 \mathrm{mg}$ during a single day, subsequently, produces blood levels of $2.5 \mathrm{mg} / \mathrm{L}$, reaching as high as $3 \mathrm{mg} / \mathrm{L}$ on the second day (Melega et al., 2007). Thus, binge doses of $260 \mathrm{mg}-1 \mathrm{~g}$ produce $2.5-12 \mathrm{mg} / \mathrm{L}$ blood levels. A study conducted in Australia between 2000 and 2005 found that $68 \%$ of 371 deaths in which individuals tested positive for AMPs could be attributed directly to METH toxicity. METH concentration ranged from 0.2 to $15 \mathrm{mg} / \mathrm{L}$ (median, $0.2 \mathrm{mg} / \mathrm{L}$ ), with AMP levels registering at $0.01-2.0 \mathrm{mg} / \mathrm{L}$ (median, $0.07 \mathrm{mg} / \mathrm{L}$ ) (Kaye et al., 2008). It is important to establish that these concentrations and peak values vary greatly depending upon the routes of administration and detection technique.

Although the brain receives around $15 \%$ of the cardiac output $(114 \pm 24 \mathrm{~mL} / 100 \mathrm{~mL} / \mathrm{min})$ the concentration of METH, its distribution and metabolism varied in all the organs (Ito et al., 2003). Interestingly, the effect of METH in brain structure and activity is extensive. A study determined the distribution and bioavailability of METH in several human organs using Positron Emission Tomography, revealing a low rate of drug uptake in the brain ( $9 \mathrm{~min})$ compared to the other organs examined. Nevertheless, the prolonged clearing period $(>75 \mathrm{~min})$, suggests a neurotoxic effect due to the extended exposure to the drug (Volkow et al., 2010).

\section{PHARMACOLOGICAL METH LEVELS IN ANIMALS}

The use of animal models has been widely used to evaluate the effect of METH in the immune and nervous system, among others. One study employing a murine model estimated how METH is distributed to tissues. Tissue-to-serum METH ratios in rats are: brain, 9.7; kidney, 35.3; spleen, 14.3 (Rivière et al., 2000). Levels of METH and AMP in both female and male murine spleens measured within a $72 \mathrm{~h}$ period after treatment with $5 \mathrm{mg} / \mathrm{Kg}$ demonstrated high concentrations of METH (Male, 870, Female, $1310 \mathrm{ng} / \mathrm{g}$ ) in comparison to lower levels of AMP (Male, 130,
Female, $270 \mathrm{ng} / \mathrm{g}$ ) within the first hours after the initial injection (Saito et al., 2008). However, a typical dose of METH that is self-administered (i.v.) by rats is $0.1-0.2 \mathrm{mg} / \mathrm{kg}$ that is equivalent to a human dose (7-14 mg/70 kg) (Cook et al., 1992; Hart et al., 2008; Kuczenski et al., 2009; Krasnova et al., 2010; Kousik et al., 2014). Also, pigeons injected i.v. and intramuscularly (i.m.) with $0.8 \mathrm{mg} / \mathrm{kg}$ of METH showed $100 \%$ of bioavailability; however, i.v. absorption was three times higher than i.m. In this regard, some studies support that injection of $\mathrm{METH}$ in ranges of $3.6-10 \mathrm{mg} / \mathrm{Kg}$ are considered lethal in animals (Hendrickson et al., 2008). Similarly, a recent study showed an 8-fold higher catalytic activity of METH in rhesus macaques compared to humans due to enzymatic differences (Earla et al., 2014).

\section{MECHANISMS OF NEUROTOXICITY}

Administration of METH can increase blood-brain barrier (BBB) permeability in rodents. Moderate to high doses of METH disrupt the BBB in several regions, including the cortex, hippocampus, thalamus, hypothalamus, cerebellum, amygdala, and striatum that, in turn, are further injured by hyperthermia and, potentially, by seizures (Sharma and Kiyatkin, 2009; Yamamoto et al., 2010). Although it is unclear whether there is a relationship between BBB injury and the damage to neurotransmitter systems, $\mathrm{BBB}$ injury appears to contribute to striatal neuron degeneration rather than dopaminergic terminal damage (Bowyer et al., 2008).METH stimulates astrocytes to produce high levels of IL6 and IL-8, resulting in an inflammatory response that inhibits neurogenesis in the brain, affects sub-ventricular and hippocampal cells, reduces hippocampal progenitor cells. Similarly, METH alters gene expression on astrocytes, halting their cell cycle and proliferation (Shah et al., 2012; Jackson et al., 2014).

Mechanisms underlying METH-induced BBB damage include alterations of expression and structure in tight junctions, microglial activation, remodeling of $\mathrm{BBB}$ cytoskeleton, induction of neuroinflammatory factors, and energy related disruption. $\mathrm{METH}$, especially at high doses combined with physical exertion, can cause hyperthermia and enhance reactive oxygen species (ROS) production, thus triggering BBB breakdown (Sharma et al., 2007; Ramirez et al., 2009; Northrop and Yamamoto, 2012). METH can induce the polymerization of proteins necessary for the stability of the BBB. Therefore, when alterations in proteins occur, the permeability of the barrier is affected and migration of inflammatory cells, such as monocytes, arises more frequently (Park et al., 2013). In murine models, the administration of low and high doses of METH shows an increase in IgG immunoreactivity in the striatum (Urrutia et al., 2013).

Notably, administration of antioxidants attenuates BBB injury in acute METH toxicity models and further implicates oxidative stress in pathological effects (Sharma et al., 2007). One study suggests that METH induces the opening of the BBB by activating the nitric oxide synthases (NOS) present in the endothelial cells of the brain capillary network (Martins et al., 2013). Oxidative stress represents an imbalance between the production of ROS and the BBB's ability to readily detoxify the reactive intermediates or to repair the resulting damage.

METH also alters the expression of several tight junction proteins and increases the permeability of brain-derived primary 
microvascular endothelial cells (Mahajan et al., 2008; Ramirez et al., 2009). The use of acute high doses of METH increases the permeability of the BBB principally in the hippocampus, while downregulation of tight junction proteins such as ZO-1, Claudin-5, and occludin cause failure in the BBB, thus increasing the expression of matrix metalloproteinase (MMP)-9 in the hippocampal neurons (Martins et al., 2011). The regulation of occludin levels is important to maintain the stability of the endothelial tissue; however, METH causes the polymerization of actin thereby hindering rearrangements, ultimately leading to a functional disruption of the BBB (Park et al., 2013). MMP activation is thought to occur through several mechanisms, including oxidative stress and cytokine production (Haorah et al., 2007; McColl et al., 2008).

Collectively, these findings suggest that AMP-driven oxidative stress followed by the activation of MMPs and breakdown of tight junctions mediate $\mathrm{BBB}$ disruption; both the activation of MMPs and oxidative stress can induce inflammation which could be accompanied by an increase in cytokine production within microglia, perpetuating damage and increasing BBB permeability (Kim et al., 2005; Amantea et al., 2007; Block and Hong, 2007). The consequences of BBB disruption are widespread and may enhance the vulnerability of the brain to microbial toxins and infection (Eugenin et al., 2013).

\section{EFFECTS OF METH ON HOST IMMUNITY}

The effects of METH on host immune response have not yet been extensively described. Limited studies about the effects of METH on immune function have, however, revealed that METH use has profound immunological implications. Findings in humans, with slight variance across ethnic groups, reveal that the uptake of a particular METH isotope targets specific organ types, in which concentrations (per/mL of tissue) were highest in the kidneys and lungs; intermediate in the stomach, pancreas, liver, and spleen; and lower in the brain and heart (Volkow et al., 2010). METH use leads to profound consequences in both, innate and adaptive immunity. Hence, investigations have begun to further elucidate the cellular and molecular basis for METH's induced immune suppression, examples of which are discussed subsequently.

\section{METH ALTERATIONS OF NATURAL PHYSICAL AND CHEMICAL BARRIERS}

The skin acts as a primary physical barrier to prevent the entrance of pathogens, thereby serving as one of the innate immune response's first lines of defense (Proksch et al., 2008). Sweat glands in the skin release various bactericidal and regulatory peptides, restricting the development of pathogenic microbiota (Rieg et al., 2006). METH has been detected in sweat $2 \mathrm{~h}$ after ingestion, with traces remaining for periods of more than a week in cases wherein multiple doses were administered (Barnes et al., 2008). No previous studies exist, however, aiming to understand the effect of $\mathrm{METH}$ on microbiota and metabolites present in the skin (e.g., lactate, glycerol, pyruvate, ammonium cation, urea) (Kutyshenko et al., 2011). In this regard, the administration of drugs such as METH via injection is associated with the development of necrotizing fasciitis. Significantly, heavy daily users of METH frequently develop neurological manifestation of formication, a sensation akin to insects crawling on or under the skin. The result of formication is that users engage in constant skin "picking," often causing the formation of ulcers that frequently scar. A marked lack of hygiene among users may also be correlated to higher rates of skin infections, abscess, and cellulitis (Rusyniak, 2013).

Another common sign of METH abuse is extreme tooth decay, a condition known in the media as "METH mouth." Users with "METH mouth" have blackened, stained, or rotting teeth, even among young and/or short-term users. The exact causes of "METH mouth" are not fully understood. A common misconception is that METH directly causes the caries (Shaner et al., 2006). The leading hypothesis is that METH constricts blood vessels, thereby, limiting blood supply resulting in "dry mouth" or xerostomia (Saini et al., 2005; Goodchild and Donaldson, 2007; Heng et al., 2008; Hamamoto and Rhodus, 2009). A reduction in saliva impairs the mouth's capacity to neutralize harsh acids produced by oral bacteria after metabolizing carbohydrates, resulting in erosion of the teeth and gums and increasing the susceptibility of teeth to damage (Shaner et al., 2006; Evans et al., 2012). A more recent pilot study, however, found no difference in saliva flow rates between users and non-users despite increased saliva acidity in users and decreased buffer capacity in saliva.

The extent of tooth decay varies widely among METH users. Richards et al., found that users who snorted METH had significantly worse tooth decay than users who smoked or injected it, although all types of users suffered from dental problems (Richards and Brofeldt, 2000); however, a newer study suggests the oral route, in contrast to intravenous or intranasal, as a better predictor of "METH mouth" severity (Brown et al., 2013).

\section{ROLE OF METH ON INNATE IMMUNITY}

METH administration induces modifications in cellular components including natural killer cells (NK), dendritic cells (DCs), monocytes, macrophages, and granulocytes, indicating complex mechanisms of immunosuppression (Harms et al., 2012). METH alkalizes normally acidic organelles within macrophages, leading to the inhibition of phagocytosis and antigen presentation processes (Tallóczy et al., 2008). Similar to chloroquine, METH is a weak base capable of inducing a collapse of the $\mathrm{pH}$ gradient across acidic organelles. The microbicidal capacity of DCs and macrophages is significantly decreased after METH exposures (Tallóczy et al., 2008; Martinez et al., 2009). Furthermore, the drug reduces the number of DCs and NK cells (Saito et al., 2006; Harms et al., 2012). The reduction of monocytes (Harms et al., 2012) and macrophages in the peritoneal zone after METH administration has also been reported (Saito et al., 2008). Similarly, antigen presentation in professional phagocytes are dysregulated, diminishing the processing capacity of these cells (Harms et al., 2012). METH-treated macrophages in tissue culture displayed increased levels of pro-inflammatory cytokine TNF- $\alpha$, whereas similar cells stimulated with lipopolysaccharide (LPS) showed increased amounts of IL- $1 \beta$ and IL- 8 in addition to TNF- $\alpha$ (Liu et al., 2012). These modifications of the innate immune response can result in impaired inflammatory responses and the degradation of physical and chemical protective barriers. 


\section{METH AND INFLAMMATION}

Much of the existing literature related to METH's impact on inflammation derives from research focusing on CNS toxicity. For instance, METH increases glutamate (GLU) levels (Ito et al., 2006) and GLU receptor stimulation increases microglial activation (Thomas and Kuhn, 2005). Activation of GLU receptors increases the production of TNF- $\alpha$, IL- $1 \beta$, IL- 6 , and IL8 (Chaparro-Huerta et al., 2005; Liu et al., 2012), resulting in increased extracellular GLU levels by either inhibiting GLU uptake or increasing GLU release from activated microglia (Zou and Crews, 2005). Additionally, astrocytes play a role in METHinduced toxicity through the modulation of GLU-mediated excitotoxicity and inflammation. Astrocytes regulate extracellular concentrations of GLU, mainly via neurotransmitter uptake. For METH, the activation of cortical astrocytes appears to be caused by GLU release and protein kinase $\mathrm{C}$ activation, and is inhibited by GLU receptor antagonism (Miyatake et al., 2005). Moreover, METH's stimulation of excitatory neurotransmitters and subsequent mGluR5-mediated activation of Akt/PI3K signaling pathways leads to the release of NF-kB, which then translocates from the cytoplasm to the nucleus for the enhanced expression of IL-6 and IL-8 in astrocytes (Shah et al., 2012). The release of NF$\mathrm{kB}$ into the cytoplasm occurs via the phosphorylation of IKK by activated Akt/PI3K, which subsequently phosphorylates $\mathrm{p}$-IkB, a regulatory protein for NF-kB (Shah et al., 2012). Under normal physiologic conditions, however, astrocytes suppress microglial activation through the release of anti-inflammatory cytokines and neurotrophic factors (Neumann, 2001). For instance, astrocytes suppress microglial activation by releasing TGF- $\beta$ or IL-10 (Loftis et al., 2011).

Another mechanism by which METH facilitates inflammatory response is through the induction of oxidative stress. METH administration stimulates a substantial production of dopamine and the release of serotonin, which can undergo autoxidation processes and produce hydrogen peroxide and super-oxide radicals (Flora et al., 2003). In addition, METH can intensify cellular oxidation via the depolarization of mitochondria and, as mentioned previously, enhanced production of extracellular GLU, both of which are well known to boost levels of ROS (Shah et al., 2012). These oxidative disturbances in cellular redox status can incite the activation of various transcription factors, such as NF-kB, AP-1 or CREB, which, in turn, stimulate specific redox-regulated transcription factors that regulate gene expression for inflammatory cytokines and adhesion molecules (Shah et al., 2012).

\section{METH AND ADAPTIVE IMMUNITY}

T-cells play critical roles in orchestrating immune responses (Anderton, 2006) because their activation and proliferation are characteristic of adaptive immune responses. The mechanisms underlying the interplay between cells of the adaptive immune system and METH are currently unclear. However, the data firmly establishes that METH adversely impacts adaptive responses that render the host more susceptible to progressive diseases, particularly HIV (In et al., 2005; Martinez et al., 2009).

Murine models show that METH modifies thymic and splenic cellularity and alters peripheral $\mathrm{T}$ lymphocyte populations (In et al., 2005). High dose METH intake induces apoptotic death in rat thymic and splenic lymphocytes and produces severe immunosuppression, which could contribute to the higher rate of infections observed in chronic METH users (Harms et al., 2012; Peerzada et al., 2013). For instance, rodent studies demonstrate that METH alters cytokine response in retroviral-infections (Yu et al., 2002; Liang et al., 2008), alters gene expression of immune cells (Mahajan et al., 2006), and disturbs thymic $\mathrm{CD} 4^{+} / \mathrm{CD}^{+}$ T-cell ratios (Yu et al., 2002; In et al., 2005).

METH reduces $\mathrm{T}$ cell infiltrates in the lungs, inhibiting $\mathrm{T}$ cell proliferation and reducing the capacity of these cells to maintain a protective immune response against respiratory pathogens (Martinez et al., 2009). Similarly, METH-exposed mice demonstrated elevated levels of early response IL-6 and IL-10 in tissue homogenates, which could indicate the development of a nonprotective Th2 response against bacterial and fungal pathogens in the respiratory tract, even when Th1 cytokines are present (Peerzada et al., 2013).

An alternative mechanism for altered T-cell function is that METH modifies oxidative stress responses. As discussed earlier, the effects of oxidative stress on suppressed signal transduction, transcription factor activities, and diminished cytokine production in response to antigen stimulation in $\mathrm{T}$ cells has been documented in several model systems (Flora et al., 2003; Shah et al., 2012). The ability of reactive oxidative free radicals to impair $\mathrm{T}$ lymphocyte function has been documented in various human pathologic conditions, specifically AIDS, in which oxidative stress can hamper host control of retroviral replication (Potula et al., 2010).

Interestingly, a recent finding suggests that METH alters intracellular calcium mobilization in $\mathrm{T}$ cells, resulting in subsequent production of oxidative free radicals, a phenomenon associated with mitochondrial damage and weakened $\mathrm{T}$ cell function (Potula et al., 2010). Mitochondria serve as a source of both intracellular ROS and ATP production, a process regulated by the second messenger, calcium. METH exposure elevates levels of cytosolic calcium, however, and leads to the saturation of the electron transport chain, which contributes to the acute production of oxidative free radicals and ultimately results in oxidative alteration of proteins, loss of intracellular ATP levels in T cells and mitochondrial dysfunction (Potula et al., 2010). A compensatory down-regulation of mitochondrial proteins from chronic METH treatment can incite a long-term cellular redox imbalance, weakening T cells' ability to effectively respond to opportunistic pathogens (Potula et al., 2010; Chandramani Shivalingappa, 2012; Martins et al., 2013).

\section{METH FACILITATES THE ACQUISITION OF INFECTIOUS DISEASES}

In addition to psychosocial aberrations, infections are serious complications of chronic METH use. Moreover, the intoxicating effects of METH alter judgment and reduce inhibitions, leading people to engage in unsafe activities, increasing risk for acquiring transmissible microbes and other opportunistic infections; these findings have been documented worldwide (Plankey et al., 2007; Volkow et al., 2007; Ye et al., 2008; Sutcliffe et al., 2009; Parry et al., 2011; Borders et al., 2013; Eugenin et al., 2013; Heninger and Collins, 2013; Khan et al., 2013; Stahlman et al., 2013; Liao 
et al., 2014). Former and current drug users have higher risks to acquired sexually transmitted diseases (STDs) (Barry et al., 2009; Miller et al., 2009; Cranston et al., 2012; Javanbakht et al., 2012; Wang et al., 2012; Chew Ng et al., 2013). These infections result from the high association of METH use and inconsistent condom use, unprotected sex incentivized by money, and high-risk sexual partner types (Johnston et al., 2010; Borders et al., 2013; Stahlman et al., 2013). Hence, there are increased risks for diverse infectious diseases and these impaired individuals have a reduced capacity to combat microbial challenges (Cohen et al., 2007; Patel et al., 2013). In this regard, current clinical and empirical knowledge on the impact of METH on the acquisition of infectious diseases is discussed here.

\section{METHICILLIN-RESISTANT STAPHYLOCOCCUS AUREUS (MRSA)}

MRSA is the single most important bacterial pathogen in infections among injection drug users, with skin and soft-tissue infections (SSTI) being extremely common (Gordon and Lowy, 2005). Their incidence is difficult to estimate because such infections are often self-treated. In this regard, a study revealed that MRSA was isolated from $61 \%$ of abscesses and $53 \%$ of purulent wounds evaluated in the US emergency departments in all type of patients suggesting that it is likely that complicated cutaneous lesions in drug users are caused by this bacterium A cross-sectional study of IDUs in San Francisco found that $32 \%$ had an abscess, cellulitis, or both (Binswanger et al., 2000). Nasal carriage of MRSA is significantly increased in METH uses and MRSA disease occurs in over half of colonized drug addicts (El-Sharif and Ashour, 2008).

In addition, skin-picking is also associated with MRSA SSTI. As previously stated, METH use causes formication, which can lead to skin-picking behavior and skin breakdown. METH abusers often live in unhygienic circumstances. Moreover, unsafe injection of METH and poor injection hygiene (e.g., lack of skin cleaning before injecting), injecting with unsterile equipment and contaminated drug solutions can introduce high bacterial loads (Frontera and Gradon, 2000). Significantly, drug solutions may contain particulate matter (e.g., talc) that damage cardiac valves if injected intravenously (Frontera and Gradon, 2000). Chronic METH use may increase the incidence of cardiovascular pathology (Wijetunga et al., 2003; Yu et al., 2003) and, if injected, infective staphylococcal endocarditis (Cooper et al., 2007).

\section{STDs}

The mind-altering effects of METH cause behavioral modifications, leading people to engage in sexual activities that put them at risk for acquiring transmissible diseases (Ellis et al., 2003). In addition to HIV and hepatitis, METH use is associated with an increased risk for and incidence of other STDs, including genital warts, syphilis, gonorrhea, and chlamydia (Hirshfield et al., 2004a,b; Mansergh et al., 2006; Rhodes et al., 2007; Mimiaga et al., 2008; Barry et al., 2009; Cranston et al., 2012; Javanbakht et al., 2012; Valencia et al., 2012). In a USA study, bacterial and viral STDs were significantly more common in METH users (odds ratio 3.8), and the risk to acquire STDs in METH users was even greater than that associated with cocaine (Hirshfield et al., 2004b). Furthermore, high levels of METH use are observed in a poly-drug use lifestyle, raising sexual risky behaviors (Khan et al.,
2013). In particular, METH use is associated with increased risk for syphilis and gonorrhea in gay and bisexual men (Shoptaw et al., 2002; Wong et al., 2005; Taylor et al., 2007). In this regard, METH use is associated with the syphilis cases reported in China, including heterosexual and homosexual men and female sex workers (Kang et al., 2011; Liao et al., 2013, 2014).Furthermore, syphilis infection increases the transmission and acquisition of HIV (Xiao et al., 2010). The minimal amount of studies aiming to address the correlation between METH use and syphilis cases in several countries may dampen what role this drug plays in disease transmission and resistance to antibiotics.

\section{HEPATITIS}

METH abuse, hepatitis C virus (HCV) infection and HIV disease are overlapping epidemics in the USA and worldwide (Soriano et al., 2002; Letendre et al., 2005). Illicit drug-using individuals are at especially high risk for acquisition of and disease from $\mathrm{HCV}$ (Day et al., 2003; Hagan et al., 2005; Smyth et al., 2005). HCV results in $\sim 20,000$ infections and $8000-10,000$ deaths annually in the USA (Ye et al., 2008; Klevens et al., 2009). HCV infection is particularly associated with injection use (Gonzales et al., 2006). Notably, HCV is prevalent in HIV patients (Ranger et al., 1991). In fact, HIV-HCV co-infection is found in $50-90 \%$ of $\mathrm{HIV}$-infected drug users and chronic HCV infection increases the morbidity and mortality rates (Letendre et al., 2005; Soriano et al., 2002). Hence, a substantial proportion of METH users with or without HIV infection has HCV (Hahn et al., 2001; Miller et al., 2004; Lea et al., 2013), suggesting that METH abuse is a risk factor for HCV. Importantly, METH abuse significantly increases $\mathrm{HCV}$ penetration into the brain of HIV-infected patients, exacerbating cognitive impairments (Letendre et al., 2007). Although risky behavioral practices, such as sharing contaminated needles and sexual activity after using METH may play an important role in HCV transmission, there is relatively little information available about whether METH directly enhances HCV replication.

METH inhibits immune responses in the liver, facilitating HCV replication in human hepatocytes (Ye et al., 2008). METH inhibits intracellular interferon alpha (IFN- $\alpha$ ) expression in human hepatocytes, which is associated with increased HCV replication. In addition, METH compromises the anti-HCV effect of IFN- $\alpha$. In this regard, METH inhibits the expression of the signal transducer and activator of transcription 1, a key modulator in IFN-mediated responses. METH down-regulates the expression of IFN regulatory factor-5, a crucial transcriptional factor that activates the IFN pathway (Ye et al., 2008). The fact that METH compromises IFN- $\alpha$-mediated innate immunity against $\mathrm{HCV}$ indicates that this drug may have a cofactor role in $\mathrm{HCV}$ pathogenesis.

Although less well studied, METH also appears to increase the risk for disease due to hepatitis $A$ virus and hepatitis $B$ virus (HBV) (Gonzales et al., 2008). The factors associated with these infections are similar to that of HCV acquisition. For instance, an outbreak of HBV occurred in a group of METH-abusing individuals sharing injection drug paraphernalia (Vogt et al., 2006). Furthermore, fulminant liver failure due to HBV may be more common in the setting of METH injection (Garfein et al., 2004). 


\section{HIV}

There is compelling evidence, although limited in quantity, from both animal and in vitro studies that illicit drugs and alcohol directly affect intracellular HIV multiplication, progression to AIDS, and death. Previous research indicated that METH might influence viral entry and integration at the host genome level, promoting HIV production and viremias (Liang et al., 2008; Toussi et al., 2009; Marcondes et al., 2010; Nair and Saiyed, 2011). Specifically, findings suggest an indirect dysregulation of chemokines and costimulatory molecules via DCs, macrophages, and CD4 ${ }^{+}$T lymphocytes, enabling the pathogenesis of HIV.

$\mathrm{HIV}$ infection is highly regulated by the expression of the HIV entry co-receptors CXCR4 and CCR5. METH-treated groups demonstrated that both of these receptors exhibited up-regulated expression after METH treatment on dendritic cells, signifying increased susceptibility to HIV infection (Liang et al., 2008; Nair et al., 2009; Nair and Saiyed, 2011). In addition, METH exposure significantly reduced expression of ERK2 and up-regulated p32 MAPK genes. In general, the genes from these signaling pathways govern the regulation of cytokines (IL-2, IL-10, and TNF- $\alpha$ ) and if altered, can enhance the production of new HIV virions and deplete CD4+ T cells from the host's immune system (Nair et al., 2009; Nair and Saiyed, 2011). Similarly, METH has demonstrated influence over dopaminergic receptors in previous findings, causing increases in dopamine concentration in extracellular spaces. This excessive accumulation eventually leads to the degeneration of the striatal dopamine terminals and the formation of reactive oxidative stress molecules. In a recent study, D1 and D2 receptors were deleted and METH-treated cells were observed for changes in genetic expression of CCR5 (Nair et al., 2009). Results showed that both D1 and D2 deficient cells reversed the up-regulatory effects of METH on DCs, indicating their involvement in METH-induced HIV infectivity (Reynolds et al., 2007; Nair et al., 2009).

Some factors associated with METH abuse include emotional reasons, social stigmas, depression, heritability, patterns of childhood abuse, and low income (Semple et al., 2008). A growing body of research supports the relationship between METH use and an increase in behaviors (sexual and those related to IDU) that increase risk for HIV infection. Chronic METH use is associated with a 2-fold higher risk of HIV acquisition (Plankey et al., 2007). Among gay and bisexual men, METH is associated with high-risk sexual behavior, HIV infection, and predicts a high incidence of AIDS (Marshall et al., 2011; Nakamura et al., 2011; Lea et al., 2013). In addition to the above-mentioned factors, in a multi-cohort analysis of the LGBT (Lesbian, Gay, Bisexual and Transgender) community, other risk factors for HIV in METH users strongly correlated with young age, IDU, and depression. METH exacerbates HIV pathology, including cognitive deficits, cardiovascular compromise, dental decay, and is strongly suspected to inhibit normal immunological response to secondary infections, such as HCV (Carey et al., 2006; Gonzales et al., 2006; Cruickshank and Dyer, 2009).

HIV infection is associated with progressive $\mathrm{CD}^{+}{ }^{+} \mathrm{T}$-cell depletion and immune dysregulation. Direct neurotoxic effects of METH putatively aggravate $\mathrm{HIV}$-associated neuronal injury (Gartner and Liu, 2002; Williams and Hickey, 2002). In addition to $\mathrm{CD}^{+}{ }^{+}$T-lymphocytes, mononuclear phagocytes are primary targets for HIV. HIV-infected macrophages survive for months, actively producing and spreading the virus. METH enhances HIV replication in human macrophages by up-regulation of CCR5 expression, augmenting infectivity and reinforcing the transport of infected leukocytes across the blood brain barrier (Liang et al., 2008). METH administration significantly increases HIV-1 production by both HIV-infected monocytes and CD4 ${ }^{+}$ T-lymphocytes in vitro. METH increases HIV production and viremia in mice transgenic for a replication-competent HIV provirus and human cyclin T1 (Toussi et al., 2009). Interestingly, METH's interaction with macrophages has illustrated the downregulation of TLR9 expression, aiding in the HIV infection of these innate cells by mitigating the receptor's antiviral effects (Cen et al., 2013).

METH and HIV-1 appear to cause more neurocognitive deficits than either alone, but their interaction is poorly understood (Rippeth et al., 2004; Cadet and Krasnova, 2007). A transgenic mouse expressing the viral envelope protein gp120 in the CNS has significantly more pronounced stereotypic behavioral responses to METH relative to parental mice, providing in vivo evidence that HIV affects the brain's response to the drug (Roberts et al., 2010). Additionally, METH serves as an agonist for the NMDA (N-Methyl-D-aspartate) receptor, activating IDO and COX-2 expression as well as facilitating the eventual production of QUIN, a neurotoxin also induced during HIV infection and can expedite neuronal apoptosis when these mechanisms are combined (Nair and Samikkannu, 2012). Lastly, an evaluation of the impact of METH and Tat on the Wnt/ $\beta$-catenin signaling pathway, a neuroprotective pathway vital in various CNS functions and negatively regulates HIV-1 replication in astrocytes, revealed that they amplified the inhibitory effect, yet employed individual cascades in an astrocytoma cell line (U87MG) to suppress $\beta$-catenin-mediated signaling (Sharma et al., 2011).

HIV pathogenesis can also be enhanced through METH abuse via regulation of members from the signaling lymphocytic activation family (SLAM), which potentially indicates a mechanism by which the drug exacerbates HIV infection (Harms et al., 2012). CD150, a SLAM molecule, was up-regulated on CD4 ${ }^{+}$ $\mathrm{T}$ cells after METH treatment making these cells susceptible to HIV infection (Harms et al., 2012). METH use enhances HIV neuropathogenesis magnifying the effect of dopamine on HIV infection of macrophages (Gaskill et al., 2009). Although we are just beginning to understand the multifaceted, complex effects of METH in the context of HIV infection, the limited information available suggests that METH facilitates HIV spread, increasing immune cell dysfunction, and exacerbating neuroAIDS.

\section{OPPORTUNISTIC FUNGI}

Fungal pathogens have been recently used as empirical models to understand the impact of METH use on host homeostasis and increased permissiveness to opportunistic microorganisms. Histoplasma capsulatum is the most prevalent cause of fungal respiratory infections, representing $53.19 \%$ of cases of endemic mycoses in the US (Chu et al., 2006). Since H. capsulatum is endemic to the Midwestern USA, where METH is a critical public health issue; the fungus is an ideal model organism to 
study the impact of METH in a systemic disease model. METH abrogates normal macrophage function, resulting in accelerated disease in murine histoplasmosis (Martinez et al., 2009). METH decreases phagocytosis and killing of $H$. capsulatum by primary macrophages. METH exposed $H$. capsulatum-infected mice have increased fungal burdens, increased pulmonary inflammation, and decreased survival. METH exposure results in cytokine dysregulation, aberrant processing of yeasts within macrophages, and immobilization of MAC-1 receptors on the macrophage surface. Additionally, METH inhibits T cell proliferation and alters antibody production, both important components of adaptive immunity. Hence, it is established that METH alters the immune system of a mammalian host, resulting in enhanced disease (Martinez et al., 2009).

The encapsulated fungus Cryptococcus neoformans is the most common cause of fungal meningitis in patients with AIDS killing $=600,000$ people worldwide (Park et al., 2009). Using a systemic mouse model of infection and in vitro assays, it was recently demonstrated that $\mathrm{METH}$ stimulates fungal adhesion, capsular polysaccharide release, and biofilm formation in pulmonary tissue (Patel et al., 2013). Interestingly, structural analysis of the capsular polysaccharide of METH-exposed cryptococci revealed that METH alters the carbohydrate composition of this virulence factor, highlighting the fungus's ability to adapt to environmental stimuli, a possible explanation for its pathogenesis. Additionally, METH facilitates $C$. neoformans dissemination from the respiratory tract into the CNS. METH alters BBB integrity and modifies the expression of tight junction and adhesion molecules (Eugenin et al., 2013). These findings provide novel evidence of the impact of METH abuse on the integrity of the cells that comprise the $\mathrm{BBB}$ and protect the brain from infection.

\section{CONCLUSION AND FUTURE PERSPECTIVES}

METH use has become increasingly prevalent in recent years, creating a severe public health epidemic and societal burden. The drug adversely changes user behavior, including putting METH users at high risk for the acquisition of diverse infectious diseases. Recent studies have identified a causal linkage between METH and immune dysfunction in mature mammals. METH immunosuppression may underlie the mechanism for the rapid development of AIDS in METH users, progressing from HIV to AIDS within only a few months (CDC, 2007). Investigators are just beginning to decipher the complex effects of METH in the context of HIV infection, but the limited nature of available information suggests that this drug dramatically impacts disease. Understanding the specific mechanisms of METH abuse and HIV will require large epidemiological studies as well as the utilization of relevant animal models that reproduce salient features of HIV infection in humans and are devoid of numerous confounding factors present in human studies.

Another important question yet to be answered is how METH disarms the adaptive immune system, further rendering the host more susceptible to opportunistic infections. We recently showed that the impairment of adaptive immunity by METH diminishes the ability of mammalian hosts to mount and maintain efficient immune responses to pathogens (Martinez et al., 2009). However, the mechanisms responsible for altered regulation of
T- and B-cells in METH-exposed hosts require further study. Identification of these underlying mechanisms will highlight new therapeutic and prophylactic methods to improve immunity in the context of drug abuse. These goals are of considerable significance in the fields of immunity, host-pathogen interactions and drug abuse.

There is an urgent need for innovative METH treatment interventions to prevent the acquisition and transmission of infectious diseases. Through utilization of drug abuse treatment and community-based outreach programs, drug abusers can change their HIV risk behaviors (Garfein et al., 2010; Miller et al., 2010; Naar-King et al., 2010). Through targeted outreach and awareness programs, the prevalence of drug abuse and drug-related risk behaviors, such as needle-sharing and unsafe sexual practices, can be reduced significantly, thus decreasing the risk of disease acquisition. This is a challenge because due to recent reduction in healthcare funding usually compromises the viability of these preventive programs. Healthcare providers should be trained to recognize signs of METH addiction, and work openly and honestly with their patients to address the detrimental effects of METH addiction.

At this time, cognitive behavioral and contingency management interventions are the most effective treatments for METH addiction (Rawson et al., 2004; Roll et al., 2006). For example, the Matrix Model is a comprehensive behavioral treatment approach for the reduction of METH abuse that merges cognitive therapy, drug testing, family education, 12-Step support, individual counseling and reinforcement for nondrug-related activities (Rawson et al., 2004). Contingency management interventions also offer tangible incentives in exchange for participating in therapy and sustaining abstinence.(Roll et al., 2006) Currently, no specific medications exist that counteract the effects of METH or that prolong abstinence from the abuse of METH by an addict. However, novel anti-METH immunotherapies, primarily in the form of monoclonal antibodies and lipid-based vaccines, are in early clinical trial phases and act as pharmacokinetic antagonists, isolating METH and its metabolites from vulnerable areas in the brain and minimizing the toxic effects of the drug (Peterson et al., 2013; Rüedi-Bettschen et al., 2013; Collins et al., 2014; Hambuchen et al., 2014).

Finally, the research described to date is likely to be only the tip of the proverbial iceberg, such that numerous other diseases, especially infectious diseases, are likely to be significantly modified by METH. The propagation of this disease, along with many other viral and bacterial contagions, demonstrates the necessity for continued studies in this area of healthcare and substance abuse. Until the use of METH is strictly curtailed, the impact of METH on our society will continue to be severe.

\section{ACKNOWLEDGMENTS}

Luis R. Martinez is supported by the NYIT College of Osteopathic Medicine Start-up funds.

\section{REFERENCES}

Amantea, D., Russo, R., Gliozzi, M., Fratto, V., Berliocchi, L., Bagetta, G., et al. (2007). Early upregulation of matrix metalloproteinases following reperfusion triggers neuroinflammatory mediators in brain ischemia in rat. Int. Rev. Neurobiol. 82, 149-169. doi: 10.1016/S0074-7742(07)82008-3 
Anderton, S. M. (2006). Avoiding autoimmune disease-T cells know their limits. Trends Immunol. 27, 208-214. doi: 10.1016/j.it.2006.03.002

Barnes, A. J., Smith, M. L., Kacinko, S. L., Schwilke, E. W., Cone, E. J., Moolchan, E. T., et al. (2008). Excretion of methamphetamine and amphetamine in human sweat following controlled oral methamphetamine administration. Clin. Chem. 54, 172-180. doi: 10.1373/clinchem.2007.092304

Barry, P. M., Kent, C. K., and Klausner, J. D. (2009). Risk factors for gonorrhea among heterosexuals-San Francisco, 2006. Sex. Transm. Dis. 36, S62-S66. doi: 10.1097/OLQ.0b013e31815faab8

Binswanger, I. A., Kral, A. H., Bluthenthal, R. N., Rybold, D. J., and Edlin, B. R. (2000). High prevalence of abscesses and cellulitis among communityrecruited injection drug users in San Francisco. Clin. Infect. Dis. 30, 579-581. doi: $10.1086 / 313703$

Block, M. L., and Hong, J.-S. (2007). Chronic microglial activation and progressive dopaminergic neurotoxicity. Biochem. Soc. Trans. 35, 1127-1132. doi: 10.1042/BST0351127

Borders, T. F., Stewart, K. E., Wright, P. B., Leukefeld, C., Falck, R. S., Carlson, R. G., et al. (2013). Risky sex in rural America: longitudinal changes in a community-based cohort of methamphetamine and cocaine users. Am. J. Addict. 22, 535-542. doi: 10.1111/j.1521-0391.2013.12028.x

Bowyer, J. F., Robinson, B., Ali, S., and Schmued, L. C. (2008). Neurotoxic-related changes in tyrosine hydroxylase, microglia, myelin, and the blood-brain barrier in the caudate-putamen from acute methamphetamine exposure. Synapse 62, 193-204. doi: 10.1002/syn.20478

Brown, R. E., Group, F. M., Francisco, S., Silverstein, S. J., Morisky, D. E., Determinants, B., et al. (2013). Meth mouth severity in response to drug-use pa tt erns and dental access in methamphetamine users. CDA $J$. $41,1-8$.

Cadet, J. L., and Krasnova, I. N. (2007). Interactions of HIV and methamphetamine: cellular and molecular mechanisms of toxicity potentiation. Neurotox. Res. 12, 181-204. doi: 10.1007/BF03033915

Carey, C. L., Woods, S. P., Rippeth, J. D., Gonzalez, R., Heaton, R. K., and Grant, I. (2006). Additive deleterious effects of methamphetamine dependence and immunosuppression on neuropsychological functioning in HIV infection. AIDS Behav. 10, 185-190. doi: 10.1007/s10461-005-9056-4

CDC. (2007). Methamphetamine Use and Risk for HIV/AIDS. Atlanta, GA: US Department of Health and Human Services.

Cen, P., Ye, L., Su, Q.-J., Wang, X., Li, J.-L., Lin, X.-Q., et al. (2013). Methamphetamine inhibits Toll-like receptor 9-mediated anti-HIV activity in macrophages. AIDS Res. Hum. Retroviruses 29, 1129-1137. doi: 10.1089/AID.2012.0264

Chandramani Shivalingappa, P., Jin, H., Anantharam, V., Kanthasamy, A., and Kanthasamy, A. (2012). N-Acetyl cysteine protects against methamphetamineinduced dopaminergic neurodegeneration via modulation of redox status and autophagy in dopaminergic cells. Parkinsons. Dis. 2012, 424285. doi: $10.1155 / 2012 / 424285$

Chaparro-Huerta, V., Rivera-Cervantes, M. C., Flores-Soto, M. E., GómezPinedo, U., and Beas-Zárate, C. (2005). Proinflammatory cytokines and apoptosis following glutamate-induced excitotoxicity mediated by p38 MAPK in the hippocampus of neonatal rats. J. Neuroimmunol. 165, 53-62. doi: 10.1016/j.jneuroim.2005.04.025

Chew Ng, R. A., Samuel, M. C., Lo, T., Bernstein, K. T., Aynalem, G., Klausner, J. D., et al. (2013). Sex, drugs (methamphetamines), and the Internet: increasing syphilis among men who have sex with men in California, 2004-2008. Am. J. Public Health 103, 1450-1456. doi: 10.2105/AJPH.2012.300808

Cho, A., K., Melega, W. P., Kuczenski, R., and Segal, D. S. (2001). Relevance of pharmacokinetic parameters in animal models of methamphetamine abuse. Synapse 39, 161-166. doi: 10.1002/1098-2396(200102)39:2<161::AIDSYN7>3.0.CO;2-E

Chu, J. H., Feudtner, C., Heydon, K., Walsh, T. J., and Zaoutis, T. E. (2006). Hospitalizations for endemic mycoses: a population-based national study. Clin. Infect. Dis. 42, 822-825. doi: 10.1086/500405

Cohen, A. L., Shuler, C., McAllister, S., Fosheim, G. E., Brown, M. G., Abercrombie, D., et al. (2007). Methamphetamine use and methicillin-resistant Staphylococcus aureus skin infections. Emerg. Infect. Dis. 13, 1707-1713. doi: 10.3201/eid1311.070148

Colfax, G., and Shoptaw, S. (2005). The methamphetamine epidemic: implications for HIV prevention and treatment. Curr. HIV/AIDS Rep. 2, 194-199. doi: 10.1007/s11904-005-0016-4
Collins, K. C., Schlosburg, J. E., Lockner, J. W., Bremer, P. T., Ellis, B. A., and Janda, K. D. (2014). Lipid tucaresol as an adjuvant for methamphetamine vaccine development. Chem. Commun. (Camb.) 50, 4079-4081. doi: 10.1039/c4cc00682h

Cook, C. E., Jeffcoat, A. R., Sadler, B. M., Hill, J. M., Voyksner, R. D., Pugh, D. E., et al. (1992). Pharmacokinetics of oral methamphetamine and effects of repeated daily dosing in humans. Drug Metab. Dispos. 20, 856-862.

Cooper, H. L. F., Brady, J. E., Ciccarone, D., Tempalski, B., Gostnell, K., and Friedman, S. R. (2007). Nationwide increase in the number of hospitalizations for illicit injection drug use-related infective endocarditis. Clin. Infect. Dis. 45, 1200-1203. doi: 10.1086/522176

Cranston, R. D., Murphy, R., Weiss, R. E., Da Costa, M., Palefsky, J., Shoptaw, S., et al. (2012). Anal human papillomavirus infection in a street-based sample of drug using HIV-positive men. Int. J. STD AIDS 23, 195-200. doi: 10.1258/ijsa.2011.011169

Cruickshank, C. C., and Dyer, K. R. (2009). A review of the clinical pharmacology of methamphetamine. Addiction 104, 1085-1099. doi: 10.1111/j.13600443.2009.02564.x

Day, C., Ross, J., and Dolan, K. (2003). Hepatitis C-related discrimination among heroin users in Sydney: drug user or hepatitis C discrimination? Drug Alcohol Rev. 22, 317-321. doi: 10.1080/0959523031000154463

Downes, M. A., and Whyte, I. M. (2005). Amphetamine-induced movement disorder. Emerg. Med. Australas. 17, 277-280. doi: 10.1111/j.1742-6723.2005. 00735.x

Drug Enforcement Administration. (2007). New Data Show Significant Disruptions in U.S. Methamphetamine, Cocaine Markets Price of Meth Soars 73 Percent; Purity Down by Nearly a Third. Washington, DC: DEA Public Affairs.

Earla, R., Kumar, S., Wang, L., Bosinger, S., Li, J., Shah, A., et al. (2014). Enhanced methamphetamine metabolism in rhesus macaque as compared with human: an analysis using a novel method of liquid chromatography with tandem mass spectrometry, kinetic study, and substrate docking. Drug Metab. Dispos. 42, 2097-2108. doi: 10.1124/dmd.114.059378

El-Sharif, A., and Ashour, H. M. (2008). Community-acquired methicillin-resistant Staphylococcus aureus (CA-MRSA) colonization and infection in intravenous and inhalational opiate drug abusers. Exp. Biol. Med. (Maywood.) 233, 874-880. doi: 10.3181/0711-RM-294

Ellis, R. J., Childers, M. E., Cherner, M., Lazzaretto, D., Letendre, S., and Grant, I. (2003). Increased human immunodeficiency virus loads in active methamphetamine users are explained by reduced effectiveness of antiretroviral therapy. J. Infect. Dis. 188, 1820-1826. doi: 10.1086/379894

Eugenin, E. A., Greco, J. M., Frases, S., Nosanchuk, J. D., and Martinez, L. R. (2013). Methamphetamine alters blood brain barrier protein expression in mice, facilitating central nervous system infection by neurotropic Cryptococcus neoformans. J. Infect. Dis. 208, 699-704. doi: 10.1093/infdis/jit117

Evans, Z. P., Miller, P. M., Sftvmut, Z. F. U., Tjhojgjdbou, T., Gps, U., Boe, M. Q., et al. (2012). Methamphetamine abuse and oral health: a pilot study of "Meth Mouth." Quintessence Int. (Berl.) 43, 229-237.

Flora, G., Lee, Y. W., Nath, A., Hennig, B., Maragos, W., and Toborek, M. (2003). Methamphetamine potentiates HIV-1 tat protein-mediated activation of redoxsensitive pathways in discrete regions of the brain. Exp. Neurol. 179, 60-70. doi: 10.1006/exnr.2002.8048

Frontera, J. A., and Gradon, J. D. (2000). Right-side endocarditis in injection drug users: review of proposed mechanisms of pathogenesis. Clin. Infect. Dis. 30, 374-379. doi: 10.1086/313664

Garfein, R. S., Bower, W. A., Loney, C. M., Hutin, Y. J. F., Xia, G.-L., Jawanda, J., et al. (2004). Factors associated with fulminant liver failure during an outbreak among injection drug users with acute hepatitis B. Hepatology 40, 865-873. doi: 10.1002/hep. 20383

Garfein, R. S., Metzner, M., Cuevas, J., Bousman, C. A., and Patterson, T. (2010). Formative assessment of ARM-U: a modular intervention for decreasing risk behaviors among HIV-positive and HIV-negative methamphetamine-using MSM. Open AIDS J. 4, 105-115. doi: 10.2174/1874613601004030105

Gartner, S., and Liu, Y. (2002). Insights into the role of immune activation in HIV neuropathogenesis. J. Neurovirol. 8, 69-75. doi: 10.1080/13550280290049525

Gaskill, P. J., Calderon, T. M., Luers, A. J., Eugenin, E. A., Javitch, J. A., and Berman, J. W. (2009). Human immunodeficiency virus (HIV) infection of human macrophages is increased by dopamine: a bridge between HIV-associated neurologic disorders and drug abuse. Am. J. Pathol. 175, 1148-1159. doi: 10.2353/ajpath.2009.081067 
Gong, W., Ritter, A., Bright, D., and Doran, C. (2012). How profitable is methamphetamine dealing in Australia? Drug Alcohol Depend. 122, 208-212. doi: 10.1016/j.drugalcdep.2011.09.028

Gonzales, R., Marinelli-Casey, P., Hillhouse, M., Hunter, J., Rawson, R. A., Mooney, L., et al. (2008). Hepatitis A and B infection among methamphetamine-dependent users. J. Subst. Abuse Treat. 35, 351-352. doi: 10.1016/j.jsat.2008.05.001

Gonzales, R., Marinelli-Casey, P., Shoptaw, S., Ang, A., and Rawson, R. A. (2006). Hepatitis C virus infection among methamphetamine-dependent individuals in outpatient treatment. J. Subst. Abuse Treat. 31, 195-202. doi: 10.1016/j.jsat.2006.04.006

Goodchild, J. H., and Donaldson, M. (2007). Methamphetamine abuse and dentistry: a review of the literature and presentation of a clinical case. Quintessence Int. 38, 583-590.

Gordon, R. J., and Lowy, F. D. (2005). Bacterial infections in drug users. N. Engl. J. Med. 353, 1945-1954. doi: 10.1056/NEJMra042823

Hagan, H., Thiede, H., and Des Jarlais, D. C. (2005). HIV/hepatitis C virus coinfection in drug users: risk behavior and prevention. AIDS 19(Suppl. 3), S199-S207. doi: 10.1097/01.aids.0000192090.61753.d4

Hahn, J. A., Page-Shafer, K., Lum, P. J., Ochoa, K., and Moss, A. R. (2001). Hepatitis $\mathrm{C}$ virus infection and needle exchange use among young injection drug users in San Francisco. Hepatology 34, 180-187. doi: 10.1053/jhep.2001. 25759

Hamamoto, D. T., and Rhodus, N. L. (2009). Methamphetamine abuse and dentistry. Oral Dis. 15, 27-37. doi: 10.1111/j.1601-0825.2008.01459.x

Hambuchen, M. D., Rüedi-Bettschen, D., Williams, D. K., Hendrickson, H., and Owens, S. M. (2014). Treatment of rats with an anti-(+)-methamphetamine monoclonal antibody shortens the duration of action of repeated (+)methamphetamine challenges over a one month period. Vaccine 32, 6213-6219. doi: 10.1016/j.vaccine.2014.09.025

Haorah, J., Ramirez, S. H., Schall, K., Smith, D., Pandya, R., and Persidsky, Y. (2007). Oxidative stress activates protein tyrosine kinase and matrix metalloproteinases leading to blood-brain barrier dysfunction. J. Neurochem. 101, 566-576. doi: 10.1111/j.1471-4159.2006.04393.x

Harms, R., Morsey, B., Boyer, C. W., Fox, H. S., and Sarvetnick, N. (2012). Methamphetamine administration targets multiple immune subsets and induces phenotypic alterations suggestive of immunosuppression. PLoS ONE 7:e49897. doi: 10.1371/journal.pone.0049897

Harris, D. S., Boxenbaum, H., Everhart, E. T., Sequeira, G., Mendelson, J. E., and Jones, R. T. (2003). The bioavailability of intranasal and smoked methamphetamine. Clin. Pharmacol. Ther. 74, 475-486. doi: 10.1016/j.clpt.2003.08.002

Hart, C. L., Gunderson, E. W., Perez, A., Kirkpatrick, M. G., Thurmond, A., Comer, S. D., et al. (2008). Acute physiological and behavioral effects of intranasal methamphetamine in humans. Neuropsychopharmacology 33, 1847-1855. doi: 10.1038/sj.npp.1301578

Hendrickson, H. P., Hardwick, W. C., McMillan, D. E., and Owens, S. M. (2008). Bioavailability of (+)-methamphetamine in the pigeon following an intramuscular dose. Pharmacol. Biochem. Behav. 90, 382-386. doi: 10.1016/j.pbb.2008.03.012

Heng, C. K., Badner, V. M., and Schiop, L. A. (2008). Meth mouth. N.Y. State Dent. J. 74, 50-51.

Heninger, M., and Collins, K., a (2013). Acute bacterial meningitis with coincident methamphetamine use: a case report and review of the literature. J. Forensic Sci. 58, 1088-1091. doi: 10.1111/1556-4029.12176

Hirshfield, S., Remien, R. H., Humberstone, M., Walavalkar, I., and Chiasson, M., (2004a). Substance use and high-risk sex among men who have sex with men: a national online study in the USA. AIDS Care 16, 1036-1047. doi: 10.1080/09540120412331292525

Hirshfield, S., Remien, R. H., Walavalkar, I., and Chiasson, M. A. (2004b). Crystal methamphetamine use predicts incident STD infection among men who have sex with men recruited online: a nested case-control study. J. Med. Internet Res. 6:e41. doi: 10.2196/jmir.6.4.e41

In, S.-W., Son, E.-W., Rhee, D.-K., and Pyo, S. (2005). Methamphetamine administration produces immunomodulation in mice. J. Toxicol. Environ. Health. A 68, 2133-2145. doi: 10.1080/15287390500177156

Ito, H., Kanno, I., Ibaraki, M., Hatazawa, J., and Miura, S. (2003). Changes in human cerebral blood flow and cerebral blood volume during hypercapnia and hypocapnia measured by positron emission tomography. J. Cereb. Blood Flow Metab. 23, 665-670. doi: 10.1097/01.WCB.0000067721.64998.F5
Ito, K., Abekawa, T., and Koyama, T. (2006). Relationship between development of cross-sensitization to MK-801 and delayed increases in glutamate levels in the nucleus accumbens induced by a high dose of methamphetamine. Psychopharmacology (Berl.) 187, 293-302. doi: 10.1007/s00213-006-0423-2

Jackson, A. R., Shah, A., and Kumar, A. (2014). Methamphetamine alters the normal progression by inducing cell cycle arrest in astrocytes. PLOS ONE 9:e109603. doi: 10.1371/journal.pone.0109603

Javanbakht, M., Gorbach, P., Stirland, A., Chien, M., Kerndt, P., and Guerry, S. (2012). Prevalence and correlates of rectal Chlamydia and gonorrhea among female clients at sexually transmitted disease clinics. Sex. Transm. Dis. 39, 917-922. doi: 10.1097/OLQ.0b013e31826ae9a2

Johnston, C. L., Callon, C., Li, K., Wood, E., and Kerr, T. (2010). Offer of financial incentives for unprotected sex in the context of sex work. Drug Alcohol Rev. 29, 144-149. doi: 10.1111/j.1465-3362.2009.00091.x

Kang, D., Liao, M., Jiang, Z., Zhang, X., Mao, W., Zhang, N., et al. (2011). Commercial sex venues, syphilis and methamphetamine use among female sex workers. AIDS Care 23(Suppl. 1), 26-36. doi: 10.1080/09540121.2011. 560930

Kaye, S., Darke, S., Duflou, J., and McKetin, R. (2008). Methamphetamine-related fatalities in Australia: demographics, circumstances, toxicology and major organ pathology. Addiction 103, 1353-1360. doi: 10.1111/j.1360-0443.2008.02231.x

Khan, M. R., Berger, A., Hemberg, J., O’Neill, A., Dyer, T. P., and Smyrk, K. (2013). Non-injection and injection drug use and STI/HIV risk in the United States: the degree to which sexual risk behaviors versus sex with an STI-infected partner account for infection transmission among drug users. AIDS Behav. 17, 1185-1194. doi: 10.1007/s10461-012-0276-0

Kim, Y. S., Kim, S. S., Cho, J. J., Choi, D. H., Hwang, O., Shin, D. H., et al. (2005). Matrix metalloproteinase-3: a novel signaling proteinase from apoptotic neuronal cells that activates microglia. J. Neurosci. 25, 3701-3711. doi: 10.1523/JNEUROSCI.4346-04.2005

Klevens, R. M., Miller, J., Vonderwahl, C., Speers, S., Alelis, K., Sweet, K., et al. (2009). Population-based surveillance for hepatitis C virus, United States, 20062007. Emerg. Infect. Dis. 15, 1499-1502. doi: 10.3201/eid1509.081050

Kousik, S. M., Napier, T. C., Ross, R. D., Sumner, D. R., and Carvey, P. M. (2014). Dopamine receptors and the persistent neurovascular dysregulation induced by methamphetamine self-administration in rats. J. Pharmacol. Exp. Ther. 351, 432-439. doi: 10.1124/jpet.114.217802

Krasnova, I. N., Justinova, Z., Ladenheim, B., Jayanthi, S., McCoy, M. T., Barnes, C., et al. (2010). Methamphetamine self-administration is associated with persistent biochemical alterations in striatal and cortical dopaminergic terminals in the rat. PLoS ONE 5:e8790. doi: 10.1371/journal.pone.0008790

Kuczenski, R., Segal, D. S., Melega, W. P., Lacan, G., and McCunney, S. J. (2009). Human methamphetamine pharmacokinetics simulated in the rat: behavioral and neurochemical effects of a 72-h binge. Neuropsychopharmacology 34, 2430-2441. doi: 10.1038/npp.2009.73

Kutyshenko, V. P., Molchanov, M., Beskaravayny, P., Uversky, V. N., and Timchenko, M., a (2011). Analyzing and mapping sweat metabolomics by high-resolution NMR spectroscopy. PLoS ONE 6:e28824. doi: 10.1371/journal.pone.0028824

Lea, T., Mao, L., Bath, N., Prestage, G., Zablotska, I., de Wit, J., et al. (2013). Injecting drug use among gay and bisexual men in Sydney: prevalence and associations with sexual risk practices and HIV and hepatitis $\mathrm{C}$ infection. AIDS Behav. 17, 1344-1351. doi: 10.1007/s10461-013-0409-0

Letendre, S. L., Cherner, M., Ellis, R. J., Marquie-Beck, J., Gragg, B., Marcotte, T., et al. (2005). The effects of hepatitis C, HIV, and methamphetamine dependence on neuropsychological performance: biological correlates of disease. AIDS 19(Suppl. 3), S72-S78. doi: 10.1097/01.aids.0000192073. 18691.ff

Letendre, S., Paulino, A. D., Rockenstein, E., Adame, A., Crews, L., Cherner, M., et al. (2007). Pathogenesis of hepatitis C virus coinfection in the brains of patients infected with HIV. J. Infect. Dis. 196, 361-370. doi: 10.1086/519285

Li, L., Everhart, T., Jacob III, P., Jones, R., and Mendelson, J. (2010). Stereoselectivity in the human metabolism of methamphetamine. Br. J. Clin. Pharmacol. 69, 187-192. doi: 10.1111/j.1365-2125.2009.03576.x

Liang, H., Wang, X., Chen, H., Song, L., Ye, L., Wang, S.-H., et al. (2008). Methamphetamine enhances HIV infection of macrophages. Am. J. Pathol. 172, 1617-1624. doi: 10.2353/ajpath.2008.070971

Liao, M., Kang, D., Tao, X., Cox, C., Qian, Y., Wang, G., et al. (2014). Syndemics of syphilis, HCV infection, and methamphetamine use along the east coast of China. BMC Public Health 14:172. doi: 10.1186/1471-2458-14-172 
Liao, M., Kang, D., Tao, X., Li, J., Qian, Y., Wang, G., et al. (2013). Dual epidemics of syphilis and methamphetamine use among drug users in Shandong Province of China. AIDS Care 25, 1236-1244. doi: 10.1080/09540121.2013. 764384

Liu, X., Silverstein, P. S., Singh, V., Shah, A., Qureshi, N., and Kumar, A. (2012). Methamphetamine increases LPS-mediated expression of IL-8, TNF- $\alpha$ and IL-1 $\beta$ in human macrophages through common signaling pathways. PLoS ONE 7:e33822. doi: 10.1371/journal.pone.0033822

Loftis, J. M., Choi, D., Hoffman, W., and Huckans, M. S. (2011). Methamphetamine causes persistent immune dysregulation: a cross-species, translational report. Neurotox. Res. 20, 59-68. doi: 10.1007/s12640-010-9223-x

Mahajan, S. D., Aalinkeel, R., Sykes, D. E., Reynolds, J. L., Bindukumar, B., Adal, A., et al. (2008). Methamphetamine alters blood brain barrier permeability via the modulation of tight junction expression: implication for HIV-1 neuropathogenesis in the context of drug abuse. Brain Res. 1203, 133-148. doi: 10.1016/j.brainres.2008.01.093

Mahajan, S. D., Hu, Z., Reynolds, J. L., Aalinkeel, R., Schwartz, S. A., and Nair, M. P. N. (2006). Methamphetamine modulates gene expression patterns in monocyte derived mature dendritic cells: implications for HIV-1 pathogenesis. Mol. Diagn. Ther. 10, 257-269. doi: 10.1007/BF03256465

Mansergh, G., Purcell, D. W., Stall, R., McFarlane, M., Semaan, S., Valentine, J., et al. (2006). CDC consultation on methamphetamine use and sexual risk behavior for HIV/STD infection: summary and suggestions. Public Health Rep. 121, 127-132.

Marcondes, M. C. G., Flynn, C., Watry, D. D., Zandonatti, M., and Fox, H. S. (2010). Methamphetamine increases brain viral load and activates natural killer cells in simian immunodeficiency virus-infected monkeys. Am. J. Pathol. 177, 355-361. doi: 10.2353/ajpath.2010.090953

Marshall, B. D. L., Wood, E., Shoveller, J. A., Patterson, T. L., Montaner, J. S. G., and Kerr, T. (2011). Pathways to HIV risk and vulnerability among lesbian, gay, bisexual, and transgendered methamphetamine users: a multicohort gender-based analysis. BMC Public Health 11:20. doi: 10.1186/14712458-11-20

Martinez, L. R., Mihu, M. R., Gácser, A., Santambrogio, L., and Nosanchuk, J. D. (2009). Methamphetamine enhances histoplasmosis by immunosuppression of the host. J. Infect. Dis. 200, 131-141. doi: 10.1086/599328

Martins, T., Baptista, S., Gonçalves, J., Leal, E., Milhazes, N., Borges, F., et al. (2011). Methamphetamine transiently increases the blood-brain barrier permeability in the hippocampus: role of tight junction proteins and matrix metalloproteinase-9. Brain Res. 1411, 28-40. doi: 10.1016/j.brainres.2011. 07.013

Martins, T., Burgoyne, T., Kenny, B.-A., Hudson, N., Futter, C. E., Ambrósio, A. F., et al. (2013). Methamphetamine-induced nitric oxide promotes vesicular transport in blood-brain barrier endothelial cells. Neuropharmacology 65, 74-82. doi: 10.1016/j.neuropharm.2012.08.021

Marwick, C. (2000). NIDA seeking data on effect of fetal exposure to methamphetamine. JAMA 283, 2225-2226. doi: 10.1001/jama.283.17.2225JMN0503-2-1

McColl, B. W., Rothwell, N. J., and Allan, S. M. (2008). Systemic inflammation alters the kinetics of cerebrovascular tight junction disruption after experimental stroke in mice. J. Neurosci. 28, 9451-9462. doi: 10.1523/JNEUROSCI.267408.2008

Melega, W. P., Cho, A. K., Harvey, D., and Laæan, G. (2007). Methamphetamine blood concentrations in human abusers: application to pharmacokinetic modeling. Synapse 61, 216-220. doi: 10.1002/syn.20365

Miller, C. L., Kerr, T., Fischer, B., Zhang, R., and Wood, E. (2009). Methamphetamine injection independently predicts hepatitis $\mathrm{C}$ infection among street-involved youth in a Canadian setting. J. Adolesc. Health 44, 302-304. doi: 10.1016/j.jadohealth.2008.08.007

Miller, C. L., Wood, E., Spittal, P. M., Li, K., Frankish, J. C., Braitstein, P., et al. (2004). The future face of coinfection. JAIDS J. Acquir. Immune Defic. Syndr. 36, 743-749. doi: 10.1097/00126334-200406010-00012

Miller, K. S., Maxwell, K. D., Fasula, A. M., Parker, J. T., Zackery, S., and Wyckoff, S. C. (2010). Pre-risk HIV-prevention paradigm shift: the feasibility and acceptability of the parents matter! Program in HIV risk communities. Public Health Rep. 125(Suppl.), 38-46.

Mimiaga, M. J., Reisner, S. L., Vanderwarker, R., Gaucher, M. J., O'Connor, C., a, Medeiros, M. S., et al. (2008). Polysubstance use and HIV/STD risk behavior among Massachusetts men who have sex with men accessing
Department of Public Health mobile van services: implications for intervention development. AIDS Patient Care STDS 22, 745-751. doi: 10.1089/apc.20 07.0243

Miyatake, M., Narita, M., Shibasaki, M., Nakamura, A., and Suzuki, T. (2005). Glutamatergic neurotransmission and protein kinase $\mathrm{C}$ play a role in neuronglia communication during the development of methamphetamine-induced psychological dependence. Eur. J. Neurosci. 22, 1476-1488. doi: 10.1111/j.14609568.2005.04325.x

Naar-King, S., Parsons, J. T., Murphy, D., Kolmodin, K., and Harris, D. R. (2010). A multisite randomized trial of a motivational intervention targeting multiple risks in youth living with HIV: initial effects on motivation, self-efficacy, and depression. J. Adolesc. Health 46, 422-428. doi: 10.1016/j.jadohealth.2009.11.198

Nair, M. P. N., and Saiyed, Z. M. (2011). Effect of methamphetamine on expression of HIV coreceptors and CC-chemokines by dendritic cells. Life Sci. 88, 987-994. doi: 10.1016/j.lfs.2010.09.019

Nair, M. P. N., Saiyed, Z. M., Nair, N., Gandhi, N. H., Rodriguez, J. W., Boukli, N., et al. (2009). Methamphetamine enhances HIV-1 infectivity in monocyte derived dendritic cells. J. Neuroimmune Pharmacol. 4, 129-139. doi: 10.1007/s11481-008-9128-0

Nair, M. P. N., and Samikkannu, T. (2012). Differential regulation of neurotoxin in HIV clades: role of cocaine and methamphetamine. Curr. HIV Res. 10, 429-34. doi: 10.2174/157016212802138742

Nakamura, N., Semple, S. J., Strathdee, S. A., and Patterson, T. L. (2011). HIV risk profiles among HIV-positive, methamphetamine-using men who have sex with both men and women. Arch. Sex. Behav. 40, 793-801. doi: 10.1007/s10508-0109713-1

Neumann, H. (2001). Control of glial immune function by neurons. Glia 36, 191-199. doi: 10.1002/glia.1108

Northrop, N. A., and Yamamoto, B. K. (2012). Persistent neuroinflamatory effects of serial exposure to stress and methamphetamine on the blood-brain barrier. J. Neuroimmune Pharmacol. 7, 951-968. doi: 10.1007/s11481-012-9391y.Persistent

Panenka, W. J., Procyshyn, R. M., Lecomte, T., MacEwan, G. W., Flynn, S. W., Honer, W. G., et al. (2013). Methamphetamine use: a comprehensive review of molecular, preclinical and clinical findings. Drug Alcohol Depend. 129, 167-179. doi: 10.1016/j.drugalcdep.2012.11.016

Park, B. J., Wannemuehler, K. A., Marston, B. J., Govender, N., Pappas, P. G., and Chiller, T. M. (2009). Estimation of the current global burden of cryptococcal meningitis among persons living with HIV/AIDS. AIDS 23, 525-530. doi: 10.1097/QAD.0b013e328322ffac

Park, M., Kim, H.-J., Lim, B., Wylegala, A., and Toborek, M. (2013). Methamphetamine-induced occludin endocytosis is mediated by the Arp $2 / 3$ complex-regulated actin rearrangement. J. Biol. Chem. 288, 33324-33334. doi: 10.1074/jbc.M113.483487

Parry, C. D. H., Plüddemann, A., Myers, B., Wechsberg, W. M., and Flisher, A. J. (2011). Methamphetamine use and sexual risk behaviour in Cape Town, South Africa: a review of data from 8 studies conducted between 2004 and 2007. Afr. J. Psychiatry 14, 372-376. doi: 10.4314/ajpsy.v14i5.4

Patel, D., Desai, G. M., Frases, S., Cordero, R. J. B., DeLeon-Rodriguez, C. M., Eugenin, E. A., et al. (2013). Methamphetamine enhances Cryptococcus neoformans pulmonary infection and dissemination to the brain. MBio 4:e0400-13. doi: $10.1128 / \mathrm{mBio} .00400-13$

Peerzada, H., Gandhi, J. A., Guimaraes, A. J., Nosanchuk, J. D., and Martinez, L. R. (2013). Methamphetamine administration modifies leukocyte proliferation and cytokine production in murine tissues. Immunobiology 218, 1063-1068. doi: 10.1016/j.imbio.2013.02.001

Peterson, E. C., Celikel, R., Gokulan, K., and Varughese, K. I. (2013). Structural characterization of a therapeutic anti-methamphetamine antibody fragment: oligomerization and binding of active metabolites. PLOS ONE 8:e82690. doi: 10.1371/journal.pone.0082690

Plankey, M. W., Ostrow, D. G., Stall, R., Cox, C., Li, X., Peck, J., et al. (2007). The relationship between methamphetamine and popper use and risk of HIV seroconversion in the multicenter AIDS cohort study. J. Acquir. Immune Defic. Syndr. 45, 85-92. doi: 10.1097/QAI.0b013e3180417c99

Potula, R., Hawkins, B. J., Cenna, J. M., Fan, S., Dykstra, H., Ramirez, S. H., et al. (2010). Methamphetamine causes mitrochondrial oxidative damage in human T lymphocytes leading to functional impairment. J. Immunol. 185, 2867-2876. doi: 10.4049/jimmunol.0903691 
Proksch, E., Brandner, J. M., and Jensen, J.-M. (2008). The skin: an indispensable barrier. Exp. Dermatol. 17, 1063-1072. doi: 10.1111/j.1600-0625.2008.00786.x

Ramirez, S. H., Potula, R., Fan, S., Eidem, T., Papugani, A., Reichenbach, N., et al. (2009). Methamphetamine disrupts blood-brain barrier function by induction of oxidative stress in brain endothelial cells. J. Cereb Blood Flow Metab. 29, 1933-1945. doi: 10.1038/jcbfm.2009.112

Ranger, S., Aussel, L., Weinbreck, P., Loustaud, V., Rogues, A. M., Mounier, M., et al. (1991). [Seroprevalence of hepatitis C in human immunodeficiency virus infected patients]. Pathol. Biol. (Paris.) 39, 126-30.

Rawson, R. A., Marinelli-Casey, P., Anglin, M. D., Dickow, A., Frazier, Y., Gallagher, C., et al. (2004). A multi-site comparison of psychosocial approaches for the treatment of methamphetamine dependence. Addiction 99, 708-717. doi: 10.1111/j.1360-0443.2004.00707.x

Reynolds, J. L., Mahajan, S. D., Sykes, D. E., Schwartz, S. A., and Nair, M. P. N. (2007). Proteomic analyses of methamphetamine (METH)-induced differential protein expression by immature dendritic cells (IDC). Biochim. Biophys. Acta 1774, 433-442. doi: 10.1016/j.bbapap.2007.02.001

Rhodes, S. D., Hergenrather, K. C., Yee, L. J., Knipper, E., Wilkin, A. M., and Omli, M. R. (2007). Characteristics of a sample of men who have sex with men, recruited from gay bars and Internet chat rooms, who report methamphetamine use. AIDS Patient Care STDS 21, 575-583. doi: 10.1089/apc.2007.0002

Richards, J. R., and Brofeldt, B. T. (2000). Patterns of tooth wear associated with methamphetamine use. J. Periodontol. 71, 1371-1374. doi: 10.1902/jop.2000.71.8.1371

Rieg, S., Seeber, S., Steffen, H., Humeny, A., Kalbacher, H., Stevanovic, S., et al. (2006). Generation of multiple stable dermcidin-derived antimicrobial peptides in sweat of different body sites. J. Invest. Dermatol. 126, 354-365. doi: 10.1038/sj.jid.5700041

Rippeth, J. D., Heaton, R. K., Carey, C. L., Marcotte, T. D., Moore, D. J., Gonzalez, R., et al. (2004). Methamphetamine dependence increases risk of neuropsychological impairment in HIV infected persons. J. Int. Neuropsychol. Soc. 10, 1-14. doi: 10.1017/S1355617704101021

Rivière, G. J., Gentry, W. B., and Owens, S. M. (2000). Disposition of methamphetamine and its metabolite amphetamine in brain and other tissues in rats after intravenous administration. J. Pharmacol. Exp. Ther. 292, 1042-1047.

Roberts, A. J., Maung, R., Sejbuk, N. E., Ake, C., and Kaul, M. (2010). Alteration of Methamphetamine-induced stereotypic behaviour in transgenic mice expressing HIV-1 envelope protein gp120. J. Neurosci. Methods 186, 222-225. doi: 10.1016/j.jneumeth.2009.11.007

Roll, J. M., Petry, N. M., Stitzer, M. L., Brecht, M. L., Peirce, J. M., McCann, M. J., et al. (2006). Contingency management for the treatment of methamphetamine use disorders. Am. J. Psychiatry 163, 1993-1999. doi: 10.1176/appi.ajp.163.11.1993

Rüedi-Bettschen, D., Wood, S. L., Gunnell, M. G., West, C. M., Pidaparthi, R. R., Carroll, F. I., et al. (2013). Vaccination protects rats from methamphetamineinduced impairment of behavioral responding for food. Vaccine 31, 4596-4602. doi: 10.1016/j.vaccine.2013.07.038

Rusyniak, D. E. (2013). Neurologic manifestations of chronic methamphetamine abuse. Psychiatr. Clin. North Am. 36, 261-275. doi: 10.1016/j.psc.2013. 02.005

Saini, T., Edwards, P. C., Kimmes, N. S., Carroll, L. R., Shaner, J. W., and Dowd, F. J. (2005). Etiology of xerostomia and dental caries among methamphetamine abusers. Oral Health Prev. Dent. 3, 189-195. doi: 10.3290/j.ohpd.a10643

Saito, M., Terada, M., Kawata, T., Ito, H., Shigematsu, N., Kromkhun, P., et al. (2008). Effects of single or repeated administrations of methamphetamine on immune response in mice. Exp. Anim. 57, 35-43. doi: 10.1538/expanim.57.35

Saito, M., Yamaguchi, T., Kawata, T., and Ito, H. (2006). Effects of methamphetamine on cortisone concentration, nk cell activity and mitogen response of t-lymphocytes in female cynomolgus monkeys. Exp. Anim 55, 477-481. doi: 10.1538/expanim. 55.477

Semple, S. J., Zians, J., Strathdee, S. A., and Patterson, T. L. (2008). Methamphetamine-using felons: psychosocial and behavioral characteristics. Am. J. Addict. 17, 28-35. doi: 10.1080/10550490701756294

Shah, A., Silverstein, P. S., Singh, D. P., and Kumar, A. (2012). Involvement of metabotropic glutamate receptor 5, AKT/PI3K signaling and NF-кB pathway in methamphetamine-mediated increase in IL-6 and IL-8 expression in astrocytes. J. Neuroinflammation 9, 52. doi: 10.1186/1742-20 94-9-52
Shaner, J. W., Kimmes, N., Saini, T., and Edwards, P. (2006). "Meth mouth": rampant caries in methamphetamine abusers. AIDS Patient Care STDS 20, 146-150. doi: 10.1089/apc.2006.20.146

Sharma, A., Hu, X.-T., Napier, T. C., and Al-Harthi, L. (2011). Methamphetamine and HIV-1 Tat down regulate $\beta$-catenin signaling: implications for methampetamine abuse and HIV-1 co-morbidity. J. Neuroimmune Pharmacol. 6, 597-607. doi: 10.1007/s11481-011-9295-2

Sharma, H. S., and Kiyatkin, E. A. (2009). Rapid morphological brain abnormalities during acute methamphetamine intoxication in the rat: an experimental study using light and electron microscopy. J. Chem. Neuroanat. 37, 18-32. doi: 10.1016/j.jchemneu.2008.08.002

Sharma, H. S., Sjöquist, P.-O., and Ali, S. F. (2007). Drugs of abuse-induced hyperthermia, blood-brain barrier dysfunction and neurotoxicity: neuroprotective effects of a new antioxidant compound H-290/51. Curr. Pharm. Des. 13, 1903-1923. doi: 10.2174/138161207780858375

Shoptaw, S., Reback, C. J., and Freese, T. E. (2002). Patient characteristics, HIV serostatus, and risk behaviors among gay and bisexual males seeking treatment for methamphetamine abuse and dependence in Los Angeles. J. Addict. Dis. 21, 91-105. doi: 10.1300/J069v21n01

Smyth, B. P., Barry, J., and Keenan, E. (2005). Irish injecting drug users and hepatitis C: the importance of the social context of injecting. Int. J. Epidemiol. 34, 166-172. doi: 10.1093/ije/dyh347

Soriano, V., Sulkowski, M., Bergin, C., Hatzakis, A., Cacoub, P., Katlama, C., et al. (2002). Care of patients with chronic hepatitis C and HIV co-infection: recommendations from the HIV-HCV International Panel. AIDS 16, 813-828. doi: 10.1097/00002030-200204120-00001

Stahlman, S., Javanbakht, M., Stirland, A., Guerry, S., and Gorbach, P. M (2013). Methamphetamine use among women attending sexually transmitted disease clinics in Los Angeles County. Sex. Transm. Dis. 40, 632-638. doi: 10.1097/01.OLQ.0000430801.14841.75

Sutcliffe, C. G., Aramrattana, A., Sherman, S. G., Sirirojn, B., German, D., Wongworapat, K., et al. (2009). Incidence of HIV and sexually transmitted infections and risk factors for acquisition among young methamphetamine users in northern Thailand. Sex. Transm. Dis. 36, 284-289. doi: 10.1097/OLQ.0b013e318191ba17

Tallóczy, Z., Martinez, J., Joset, D., Ray, Y., Gácser, A., Toussi, S., et al. (2008). Methamphetamine inhibits antigen processing, presentation, and phagocytosis. PLoS Pathog. 4:e28. doi: 10.1371/journal.ppat.0040028

Taylor, M. M., Aynalem, G., Smith, L. V., Montoya, J., and Kerndt, P. (2007) Methamphetamine use and sexual risk behaviours among men who have sex with men diagnosed with early syphilis in Los Angeles County. Int. J. STD AIDS 18, 93-97. doi: 10.1258/095646207779949709

Thomas, D. M., and Kuhn, D. M. (2005). MK-801 and dextromethorphan block microglial activation and protect against methamphetamine-induced neurotoxicity. Brain Res. 1050, 190-198. doi: 10.1016/j.brainres.2005.05.049

Toussi, S. S., Joseph, A., Zheng, J. H., Dutta, M., Santambrogio, L., and Goldstein, H. (2009). Short communication: Methamphetamine treatment increases in vitro and in vivo HIV replication. AIDS Res. Hum. Retroviruses 25, 1117-1121. doi: 10.1089/aid.2008.0282

United Nations. (2011). Amphetamines and Ecstasy: 2011 Global ATS Assessment. Vienna: United Nations Office on Drugs and Crime.

Urbina, J. A., Concepcion, J. L., Caldera, A., Payares, G., Sanoja, C., Otomo, T., et al. (2004). In vitro and in vivo activities of E5700 and ER-119884, two novel orally active squalene synthase inhibitors, against Trypanosoma cruzi. Antimicrob. Agents Chemother. 48, 2379-2387. doi: 10.1128/AAC.48.7.2379-23 87.2004

Urrutia, A., Rubio-Araiz, A., Gutierrez-Lopez, M. D., ElAli, A., Hermann, D. M., O'Shea, E., et al. (2013). A study on the effect of JNK inhibitor, SP600125, on the disruption of blood-brain barrier induced by methamphetamine. Neurobiol. Dis. 50, 49-58. doi: 10.1016/j.nbd.2012.10.006

Valencia, F., Bubar, M. J., Milligan, G., Cunningham, K. A., and Bourne, N. (2012). Influence of methamphetamine on genital herpes simplex virus type 2 infection in a mouse model. Sex. Transm. Dis. 39, 720-7255. doi: 10.1097/OLQ.0b013e31825af129

Vogt, T. M., Perz, J. F., Van Houten, C. K., Harrington, R., Hansuld, T., Bialek, S. R., et al. (2006). An outbreak of hepatitis B virus infection among methamphetamine injectors: the role of sharing injection drug equipment. Addiction 101, 726-730. doi: 10.1111/j.1360-0443.2006.01407.x 
Volkow, N. D., Fowler, J. S., Wang, G.-J., Shumay, E., Telang, F., Thanos, P. K., et al. (2010). Distribution and pharmacokinetics of methamphetamine in the human body: clinical implications. PLoS ONE 5:e15269. doi: 10.1371/journal.pone.0015269

Volkow, N. D., Wang, G.-J., Fowler, J. S., Telang, F., Jayne, M., and Wong, C. (2007). Stimulant-induced enhanced sexual desire as a potential contributing factor in HIV transmission. Am. J. Psychiatry 164, 157-160. doi: 10.1176/appi.ajp.164.1.157

Wang, X., Wang, Y., Ye, L., Li, J., Zhou, Y., Sakarcan, S., et al. (2012). Modulation of intracellular restriction factors contributes to methamphetamine-mediated enhancement of acquired immune deficiency syndrome virus infection of macrophages. Curr. HIV Res. 10, 407-414. doi: 10.2174/157016212802 138797

Wijetunga, M., Seto, T., Lindsay, J., and Schatz, I. (2003). Crystal methamphetamine-associated cardiomyopathy: tip of the iceberg? J. Toxicol. Clin. Toxicol. 41, 981-986. doi: 10.1081/CLT-120026521

Williams, K. C., and Hickey, W. F. (2002). Central nervous system damage, monocytes and macrophages, and neurological disorders in AIDS. Annu. Rev. Neurosci. 25, 537-562. doi: 10.1146/annurev.neuro.25.112701.142822

Wong, W., Chaw, J. K., Kent, C. K., and Klausner, J. D. (2005). Risk Factors for Early Syphilis Among Gay and Bisexual Men Seen in an STD Clinic: San Francisco, 2002???2003. Sex. Transm. Dis. 32, 458-463. doi: 10.1097/01.olq.0000168280.34424.58

Xiao, Y., Sun, J., Li, C., Lu, F., Allen, K. L., Vermund, S. H., et al. (2010). Prevalence and correlates of HIV and syphilis infections among men who have sex with men in seven provinces in China with historically low HIV prevalence. J. Acquir. Immune Defic. Syndr. 53(Suppl. 1), S66-S73. doi: 10.1097/QAI.0b013e3181c7db43

Yamamoto, B. K., Moszczynska, A., and Gudelsky, G. A. (2010). Amphetamine toxicities: classical and emerging mechanisms. Ann. N.Y. Acad. Sci. 1187, 101-121. doi: 10.1111/j.1749-6632.2009.05141.x
Ye, L., Peng, J. S., Wang, X., Wang, Y. J., Luo, G. X., and Ho, W. Z. (2008). Methamphetamine enhances Hepatitis $\mathrm{C}$ virus replication in human hepatocytes. J. Viral Hepat. 15, 261-270. doi: 10.1111/j.1365-2893.2007.00940.x

Yu, Q., Larson, D. F., and Watson, R. R. (2003). Heart disease, methamphetamine and AIDS. Life Sci. 73, 129-140. doi: 10.1016/S0024-3205(03)00260-1

Yu, Q., Zhang, D., Walston, M., Zhang, J., Liu, Y., and Watson, R. R. (2002). Chronic methamphetamine exposure alters immune function in normal and retrovirus-infected mice. Int. Immunopharmacol. 2, 951-962. doi: 10.1016/S1567-5769(02)00047-4

Zou, J. Y., and Crews, F. T. (2005). TNF alpha potentiates glutamate neurotoxicity by inhibiting glutamate uptake in organotypic brain slice cultures: neuroprotection by NF kappa B inhibition. Brain Res. 1034, 11-24. doi: 10.1016/j.brainres.2004.11.014

Conflict of Interest Statement: The authors declare that the research was conducted in the absence of any commercial or financial relationships that could be construed as a potential conflict of interest.

Received: 29 October 2014; accepted: 17 December 2014; published online: 12 January 2015.

Citation: Salamanca SA, Sorrentino EE, Nosanchuk JD and Martinez LR (2015) Impact of methamphetamine on infection and immunity. Front. Neurosci. 8:445. doi: 10.3389/fnins.2014.00445

This article was submitted to Neuropharmacology, a section of the journal Frontiers in Neuroscience.

Copyright (c) 2015 Salamanca, Sorrentino, Nosanchuk and Martinez. This is an openaccess article distributed under the terms of the Creative Commons Attribution License (CC BY). The use, distribution or reproduction in other forums is permitted, provided the original author(s) or licensor are credited and that the original publication in this journal is cited, in accordance with accepted academic practice. No use, distribution or reproduction is permitted which does not comply with these terms. 